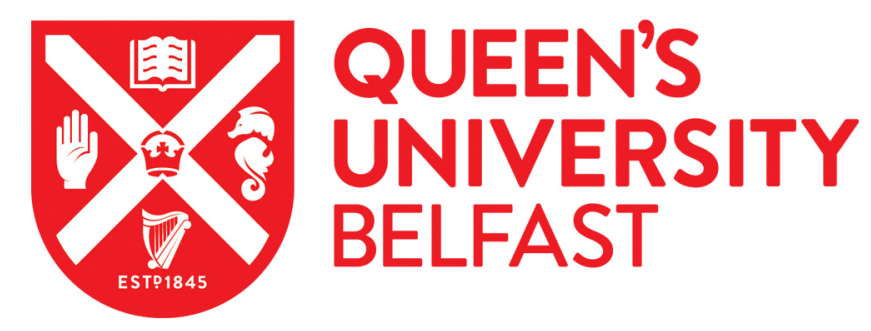

\title{
Simplified, high performance transceiver for phase modulated RFID applications
}

Buchanan, N. B., \& Fusco, V. (2015). Simplified, high performance transceiver for phase modulated RFID applications. In Proceedings of 2015 European Microwave Conference (EuMC) (pp. 104-106). Institute of Electrical and Electronics Engineers Inc.. https://doi.org/10.1109/EuMC.2015.7345710

Published in:

Proceedings of 2015 European Microwave Conference (EuMC)

Document Version:

Peer reviewed version

Queen's University Belfast - Research Portal:

Link to publication record in Queen's University Belfast Research Portal

Publisher rights

( $) 2016$ IEEE. Personal use of this material is permitted. Permission from IEEE must be obtained for all other uses, in any current or future media, including reprinting/republishing this material for advertising or promotional purposes, creating new collective works, for resale or redistribution to servers or lists, or reuse of any copyrighted component of this work in other works

\section{General rights}

Copyright for the publications made accessible via the Queen's University Belfast Research Portal is retained by the author(s) and / or other copyright owners and it is a condition of accessing these publications that users recognise and abide by the legal requirements associated with these rights.

Take down policy

The Research Portal is Queen's institutional repository that provides access to Queen's research output. Every effort has been made to ensure that content in the Research Portal does not infringe any person's rights, or applicable UK laws. If you discover content in the Research Portal that you believe breaches copyright or violates any law, please contact openaccess@qub.ac.uk. 


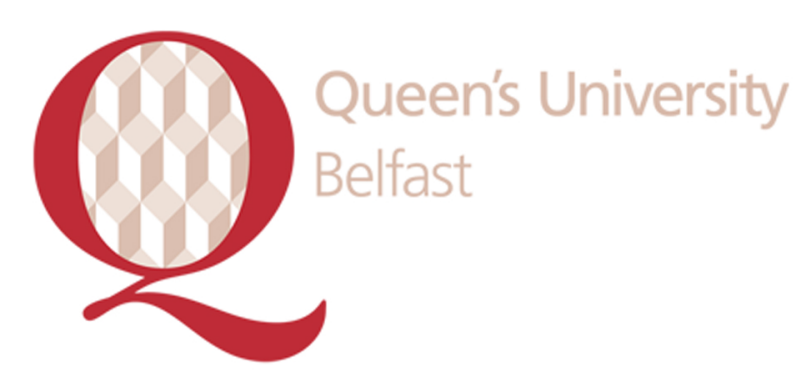

\section{Queen's University Belfast - Research Portal}

\section{Simplified, high performance transceiver for phase modulated RFID applications}

Buchanan, N. B., \& Fusco, V. (2015). Simplified, high performance transceiver for phase modulated RFID applications. 1-4.

\section{Link:}

Link to publication record in Queen's University Belfast Research Portal

\section{General rights}

Copyright for the publications made accessible via the Queen's University Belfast Research Portal is retained by the author(s) and / or other copyright owners and it is a condition of accessing these publications that users recognise and abide by the legal requirements associated with these rights.

\section{Take down policy}

The Research Portal is Queen's institutional repository that provides access to Queen's research output. Every effort has been made to ensure that content in the Research Portal does not infringe any person's rights, or applicable UK laws. If you discover content in the Research Portal that you believe breaches copyright or violates any law, please contact openaccess@qub.ac.uk. 


\title{
Simplified, high performance transceiver for phase modulated RFID applications
}

\author{
N.B. Buchanan, V. Fusco \\ The Institute of Electronics, Communications and Information Technology (ECIT), Queen's University Belfast, Northern Ireland \\ Science Park, Queen's Road, Queen's Island, Belfast, United Kingdom, BT3 9DT, Tel +44 2890971721 , Fax +44 2890971702 \\ n.buchanan@ecit.qub.ac.uk
}

\begin{abstract}
In this paper results are presented for a simple yet highly sensitive transceiver for phase modulated RFID applications. This is an advance on other simple RFID readers which can only operate with amplitude shift keyed (ASK) signals. Simple circuitry is achieved by the use of a novel injection locked PLL configuration which replaces the standard superhet type architecture normally used. The transceiver is shown to operate with a number of phase modulation modes which have certain advantages relating to distance to target. The paper concludes with practical results obtained for the transceiver when operated within a backscatter RFID application. A unique advantage of this transceiver is its complete immunity to the problem of $T X / R X$ isolation, allowing for long ranges, estimated to be in the region of $80 \mathrm{~m}$ at $1 \mathrm{GHz}$, to be achieved even in the presence of a simple backscatter target.
\end{abstract}

Keywords-Radiofrequency identification, Injection-locked oscillators, Phase locked loops, Phase shift keying

\section{Introduction}

RFID systems often employ a backscatter tag using amplitude shift keying (ASK) modulation. Amplitude shift keying allows for straightforward tag and reader hardware. However ASK is not spectrally efficient and also has poor immunity to interference, particularly in the case of multiple tags and strong interferers. The use of phase shift keying (PSK) is an attractive alternative to ASK, although the hardware, particularly regarding the reader, becomes more complicated. Fig. 1(a) shows a typical receiver architecture for a PSK RFID system [1]. Here, the reader transmits a signal to the RFID tag, which then applies some backscatter modulation onto the return signal. A conventional reader employs separate transmitters and receivers, which have a requirement for a high isolation, normally obtained using a bulky circulator as in Fig. 1(a). Assuming circulators have a typical isolation of $40 \mathrm{~dB}$, then this system will be very limited with regards to the range between reader and tag if the two way path loss is greater than $40 \mathrm{~dB}$, since the received signal will be masked by the transmit signal. This would limit such a system to a range of only $0.75 \mathrm{~m}$ at $1 \mathrm{GHz}$ if a $10 \mathrm{~dB}$ gain $\mathrm{TX} / \mathrm{RX}$ antenna was used.

To provide a solution to the complexity issue and poor TX/RX isolation of the conventional RFID reader the injection locked PLL has been proposed in [2]. This is reproduced in Fig. 1(b). The advantages of the injection locked PLL is that the implementation is very simple, employing only a voltage controlled oscillator and a PLL IC. It also does not require any isolation between the TX and RX paths and has been shown to be capable of detecting phase modulated signals as low as $-120 \mathrm{dBm}$ [2]. The injection locked PLL operates by taking advantage of the normally unwanted conflict that occurs between the phase locked loop attempting to phase lock the $\mathrm{VCO}$, and an external signal attempting to injection lock [3] the VCO. When the phase locking and injection locking are out of phase then a low frequency perturbation in the VCO control voltage is produced which can be used to demodulate amplitude shift keyed (ASK) signals or phase shift keyed (PSK) signals. It should be noted that the injection locked PLL is different in operation to other self oscillating detectors which rely on homodyne operation [4], wherein the oscillator acts like a self oscillating mixer but not operating in the oscillator injection locked region.

In this paper the advantages of the injection locked PLL with regards to demodulation of BPSK/QPSK will be shown experimentally for the first time. The paper concludes with a practical demonstration of a high performance backscatter detection system.

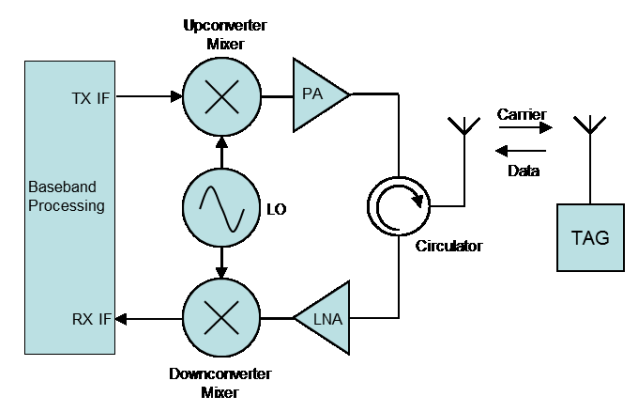

(a) Conventional RFID system

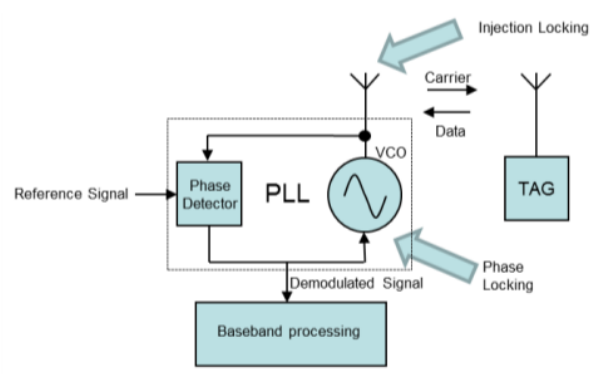

(b) Injection locked PLL

Fig. 1 Comparison of Injection locked PLL and conventional RFID system 


\section{BPSK/QPSK DEMODULATION EXPERIMENTAL RESULTS}

The injection locked PLL has huge potential where there is a need for very simple phase modulated microwave communications. The practical injection locked PLL is shown in Fig 2. It employs a commercial PLL IC (NXP UMA1021), using a first order loop filter with a cutoff frequency of $1 \mathrm{KHz}$. In this experiment we show its potential to demodulate QPSK signals. A QPSK signal was applied to the injection locked PLL as per Fig. 2. In the first scenario a QPSK bit sequence of 00011011, 2Kbps was transmitted to the injection locked PLL at $-40 \mathrm{dBm}$ power level. If we assume Gray encoding on the QPSK signal the signal phase will rotate sequentially around the constellation diagram. The result of this, as manifested on the VCO control voltage, is a demodulated signal with a repetitive pattern (Fig. 3(a)). This shows the ability of the injection locked PLL to demodulate phase shift keyed signals. Next a QPSK signal was applied with a Pseudo Random bit Sequence (PRBS). The demodulation result is shown in (Fig. $3(\mathrm{~b})$ ). Here the random nature of the PRBS signal is reproduced in the demodulated response. This response could be used to decode the PRBS data, subject to the necessary post processing, to allow for data transmission and signal authentication from the remote backscatter RFID tag.

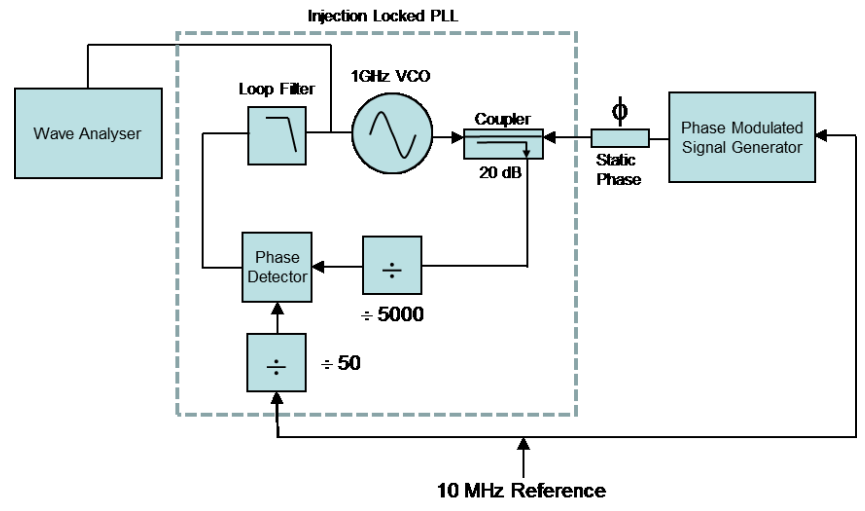

Fig. 2 Experimental setup for BPSK/QPSK demodulation

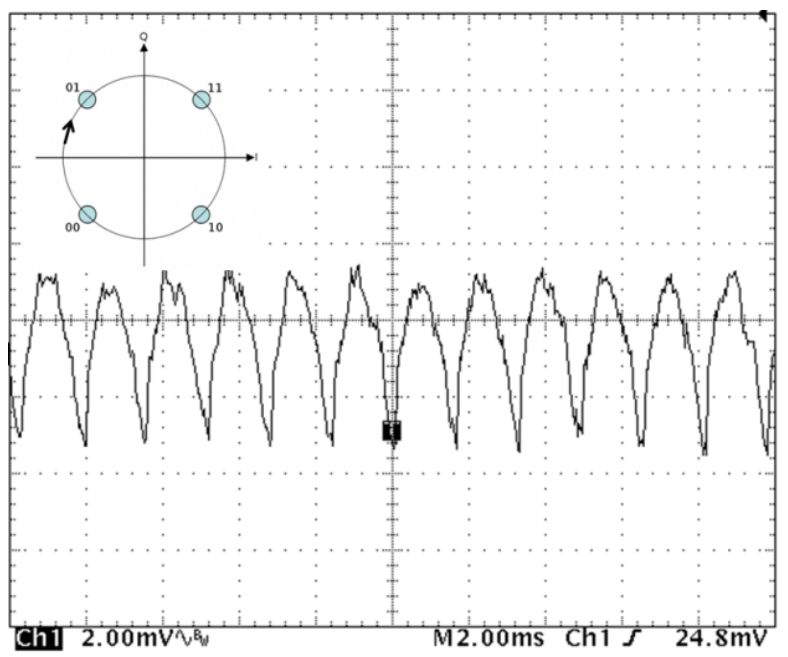

(a) QPSK 00011011 repetitive bit sequence

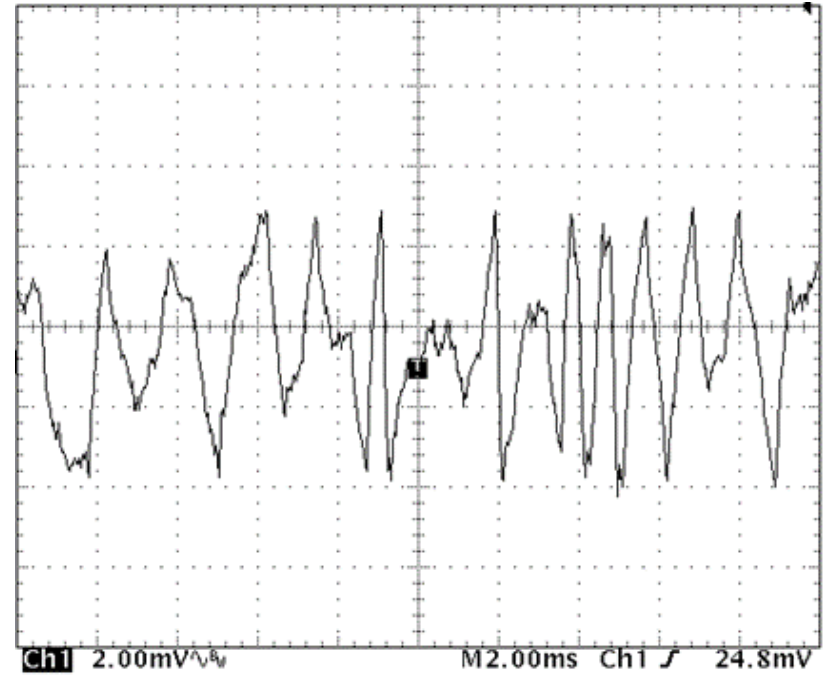

(b) QPSK PRBS (Random) bit sequence

Fig. 3 Demodulated waveforms from QPSK signals

\section{EXPERIMENTAL RESULTS OF BPSK/QPSK MODULATION WITH RESPECT TO DISTANCE TO TARGET}

The injection locked PLL is able to produce demodulated responses versus distance to target when operating with BPSK and QPSK modulation. For this experiment the modulated signal was applied to the injection locked PLL, as per Fig. 2 and a static phase was introduced to the signal, to represent small changes of distance to target. The power level applied was $-60 \mathrm{dBm}$, which would represent a typical range to a backscatter target of $10 \mathrm{~m}$ (which can be estimated from Fig. 6). The received demodulated signal amplitude was measured from the wave analyser and plotted Vs static phase delay, as shown in Fig. 4. There will be some scenarios where the degradation of demodulated signal Vs distance to target will be disadvantageous, since RFID systems employing ASK modulation would normally not be expected to have any sensitivity to distance to target. In the case of BPSK, the demodulated signal amplitude varies between maximum/minimum for every $180^{\circ}$ of static phase. This occurs because the maximum demodulated signal is only obtained when the signal presented to the VCO is in antiphase w.r.t. the phase locking from the PLL, for maximum pulling effect. The amplitude variation Vs static phase has the advantage that it could be used in scenarios where it is necessary to detect variation of distance between the RFID tag and the reader.

Using the Injection locked PLL, the variation of demodulated signal Vs target distance can be completely removed using QPSK modulation. The result of Fig. 4 shows that for QPSK there is no variation in demodulated signal over the entire $360^{\circ}$ range of static phase delay. It would therefore be expected, in a QPSK backscatter system, using the injection locked PLL, that successful signal recovery can occur regardless of variation of distance to target. 


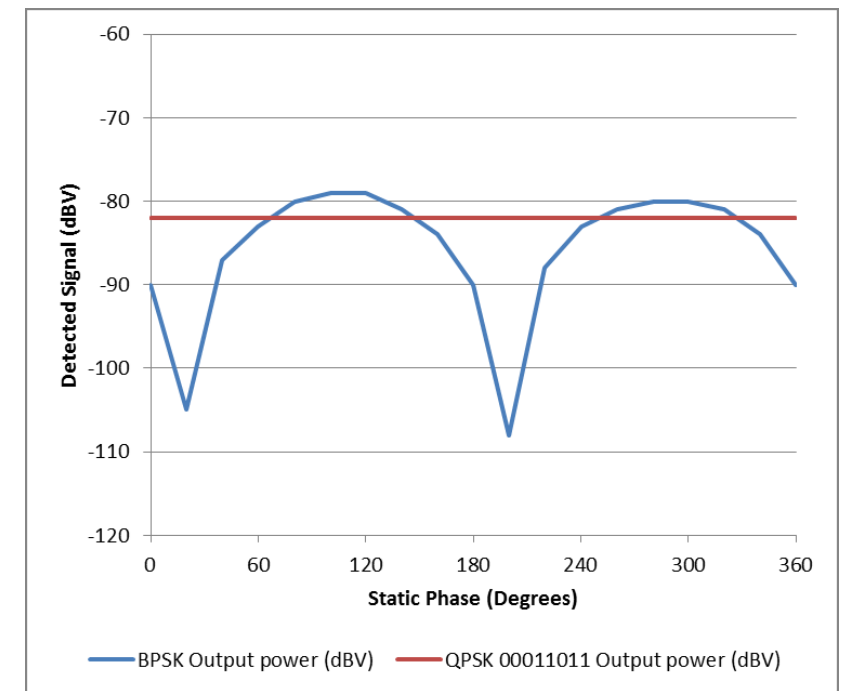

Fig. 4 BPSK/QPSK detected signal amplitude Vs static phase delay for $-60 \mathrm{dBm}$ input power

\section{PRACTICAL RESUlTS WITH RF BACKSCATTER SYSTEM}

The results so far have shown the ability of the injection locked PLL operating via a signal generator to artificially create the environment of a backscatter RFID system. To prove its operation as an actual backscatter RFID system, the setup of Fig. 5 was used. Here the injection locked PLL signal is transmitted via a $10 \mathrm{~dB}$ horn antenna to a backscatter RFID target placed at a distance of $2.5 \mathrm{~m}$. The backscatter target employs a switchable $50 \mathrm{~dB}$ amplifier to allow the amplitude of the backscatter signal to be rapidly varied.

For $500 \mathrm{~Hz}$ modulation ( $\mathrm{F}_{\mathrm{SW}}$, Fig. 5) a received peak to peak fluctuation at the $\mathrm{VCO}$ control voltage of $-51 \mathrm{dBv}$ was achieved for a $2.5 \mathrm{~m}$ range. Adding $6 \mathrm{~dB}$ additional path loss reduced this to $-57 \mathrm{dBv}$. Fig. 6 shows the sensitivity of the detector when fed with a $500 \mathrm{~Hz}$ pulse modulated signal directly. This can be used to estimate the maximum range of the backscatter system. From Fig. 6 a VCO control voltage fluctuation of $-51 \mathrm{dBv}$ (range $=2.5 \mathrm{~m}$ ) corresponds to an input power of $-38 \mathrm{dBm}$ at the injection locked PLL. The graph of Fig. 6 shows that the fluctuation is detectable down to received power level of $-100 \mathrm{dBm}$. Assuming that the two way path loss increases by $12 \mathrm{~dB}$ for every doubling of range, then operation down to $-100 \mathrm{dBm}$ would correspond to a range of $80 \mathrm{~m}$.

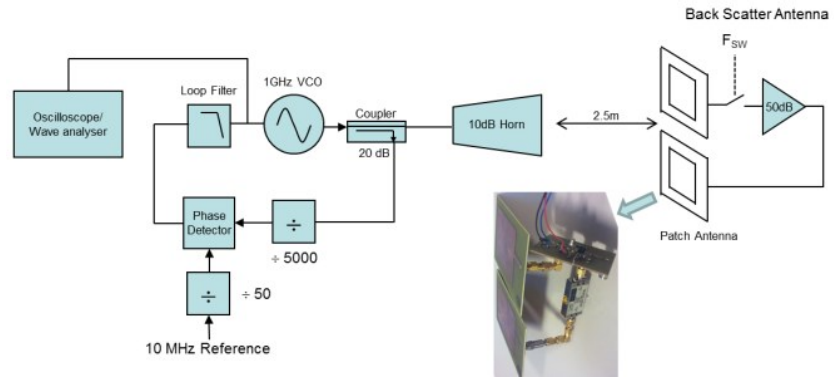

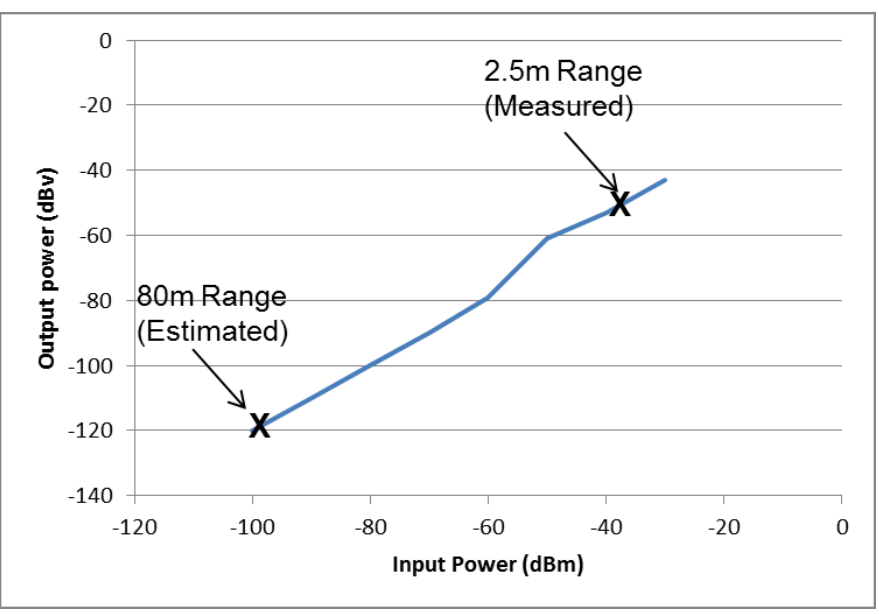

Fig. 6 Input power Vs detected output power for backscatter system, showing range estimations for a backscatter modulation frequency of $500 \mathrm{~Hz}$

\section{CONCLUSIONS}

This paper has shown, for the first time, successful demodulation of phase shift keyed signals using a novel injection locked PLL configuration. This allows for considerable simplification of RFID readers compared to the conventional super heterodyne approach. The use of BPSK modulation provides a variation in recovered signal w.r.t. distance to target, which is useful in applications where distance to target needs to be measured. In applications where the system must be robust to variations in distance to target then QPSK modulation has the advantage of no variation in recovered signal $\mathrm{Vs}$ distance to target. The system has also been proved as an actual RFID backscatter system with a potential range in the order of $80 \mathrm{~m}$ between reader and tag.

\section{REFERENCES}

[1] Xiaorong, G., Sun, J., Wang, C., and Yuan, C.: "CMOS Yields UHF RFID Transmitter" Microwaves and RF, February 2012

[2] Buchanan, N.B., Fusco, V., "Simple high Sensitivity Wireless Transceiver", Microwave and Optical Technology Letters, Vol. 56, No. 4, April 2014, pp 790-792

[3] K. Kurokawa, " Injection Locking of Microwave Solid-State Oscillators," Proceedings of the IEEE, Vol. 61, NO. 10, October 1973, pp. 1386-1392

[4] Cantu, H.I.; Fusco, V.; , "Detection sensitivity of self-pulsed selfoscillating millimetre-wave sensor," Electronics Letters , vol.43, no.23, Nov. 82007. 